\title{
Evaluation of the role of the peers in the communication with pupils who represent aggressive behaviour in the classroom environment
}

\author{
Marta BEJ \\ Specialist of Psychological Services \\ School Psychologist \\ martbej@yahoo.it
}

Abstract

\begin{abstract}
Aim: The aim of this article is to evaluate the role of peers/ school friends during the adaption phase in the school environment of children aggressive behaviour, aged 11-14 with. The article aims at identifying how the other children perceive the aggressive behaviour and how they react towards this behaviour. Methods: This is a qualitative research. The methods used are: analysing the secondary data and also information gathered by semi-structured interviews with pupils. The Interviews are part of the general research made for the PHD-theses. This study includes a sample of 20 pupils who are part of the same classrooms identified with high level of aggressive behaviour. The questions of the semi-structured interviews tend to explore how the aggressive behaviour of some children in the class affects the emotional comfort of other children. The analysis of secondary data is based on the existing literature of national and international studies and policies related to the field of aggressivity and in the high schools. Results: in general, the situation of conflicts with the expressed disruptive behaviour is seen in an resilient point of view from the peer group. They reflect conformism in some situations where they are passive part of a conflict. Most of the pupils interviewed emphasize how essential is the intervention of the teachers or an adult in cases when the conflict involves them directly. Some cases were successful just because the classmates created a comfortable environment for the aggressive children inside the classroom. The intervention of a teacher was important to resolve difficult situations in the classroom environment.Conclusions: If we contribute to have a positive environment in the classroom with the support of the teachers than we can have better quality of the emotional wellbeing of all children in the classroom.
\end{abstract}

Keywords: aggressive children; peers, emotional comfort, conflict, classroom.

\section{Introduction}

Human aggression is any behaviour directed toward another individual that is carried out with the proximate (immediate) intent to cause harm. in addition, the perpetrator must believe that the behaviour will harm the target, and that the target is motivated to avoid the behaviour (Bushman\& Anderson 2001,Baron\& Richardson 1994, Berkowitz 1993, Geen 2001). A way of interpreting this definition is that in the aggressive behaviour an important role is set by the way on how the individuals interpret the behaviour and its consequences. We deal with aggression every day in our lives and in any environment, but as Thomas \&Bierman (2006) suggested, there is mounting evidence that school environments can contribute to the socialization and promotion of childhood aggressive behaviour. Research suggests that exposure to grade school classrooms with many aggressive members may increase risk for persistent aggressive behaviour problems (Barth, Dunlap, Dane, Lochman, \& Wells, 2004; Kellam, Ling, Merisca, Brown \&lalongo, 1998). This article aims at evaluating the roles of peers/ school friends during the adaption phase in the school environment of children with aggressive behaviour, aged 1114. It is important to identify how the other children perceive the aggressive behaviour and how they react towards this behaviour. This study was conducted in a classroom identified with high level of aggressivity.

In accordance with Thomas \&Bierman (2006), there are three mechanisms that contribute to the negative impact of high aggression classrooms. First are the social norms, according to the person-group similar model (Tversky, 1997), which states that groups who have high concentrations of aggressive members create a "social" environment, in which the aggressive behaviours are seen as normal, making them socially acceptable. Second, "deviancy training" models, who suggest that aggressive children when paired tend to model, provoke or reinforce antisocial behaviour (Dishion, McCord \&Poulin, 1999). And, third, studies also suggest that classrooms that contain many aggressive-disruptive students make it difficult for teachers to forge positive relationships with students and use effective behaviour management strategies to maintain control of the classroom (Brophy, 1996; Hawkins, VonCleve, \& Catalano 1991; Hughes,Cavell, \& Jackson, 1999). The combination of these three mechanisms, contribute to the rising of aggressive behaviours in students, by being frequently exposed to them in the school environment. 
Previous research suggest that the exposure to aggressive behaviours in the classrooms, promotes increases in child aggression, but we should also mention that this impact of exposure varies in developmental timing and length (Thomas \&Bierman, 2006). This means that if this exposure occurs early in elementary school or across multiple school years, might have a stronger impact on child's aggressive behaviour and might also affect their development in competences needed for their later behaviour in life, like social, emotional and cognitive ones. in this case children trying to adapt themselves with the aggression in school environments may be part into a socialization trajectory, in which they sustain their aggressive behaviours in later school years. Recent exposure to classrooms with many aggressive peers may function as a stressor for children, contributing to heightened sensitivity to perceived threat and self-protective hostile reactivity (Coie\&Dogde, 1998). So, pupils may feel stressed while acting toward aggressive behaviour of their classmates.

Disruptive behaviour in schools has been a source of concern for school systems for several years. Indeed, the single most common request for assistance from teachers is related to behaviour and classroom management (Rose\& Gallup, 2005). Effective classroom management focuses on preventive rather than reactive procedures and establishes a positive classroom environment in which the teacher focuses on students who behave appropriately (Lewis \&Sugai, 1999). Rules and routines are powerful preventative components to classroom organization and management plans because they establish a behavioural context for the classroom that includes what is expected, what will be reinforced, and what will be retaught if inappropriate behaviour occurs (Colvin, Kame'enui, \&Sugai , 1993). This prevents problem behaviour by giving students specific, appropriate behaviours to engage in. Monitoring student behaviour allow the teacher to acknowledge students who are engaging in appropriate behaviour and prevent misbehaviour from escalating (Colvin et al., 1993). As, it will be stated below, children report that teachers play an important role, in preventing aggressive behaviours, and in dealing with conflicts that come through them.

Aggression is an issue that continues, and will continue to be a major concern, not only for educators, but also for pupils and school environment in general. If we make some effort in trying to understand how it is expressed, and how it is perceived from our pupils, we will be able to understand it better, to understand our pupil's feelings better, and to help them in order to deal with it, and also one of the most important goals of school psychologists to prevent it.

\section{Background in the Country:}

During the last decades in our country, most of the Ministry of Education and Sciences policies emphasize how important is to offer qualitative education for all the children in the country. Therefore, during this period, in Albania it was given a more special attention to the methods of positive discipline used by teachers in school environment. in the everyday reality of managing behaviour problems in classrooms, the teachers are facing lots of difficulties treating the pupils, especially pupils who represent disruptive behaviour. in terms of involvement, all the children in the elementary school (9-year schoolsystem) can frequent the system even when they behave aggressively; children who show persistent disruptive behaviour, and the teachers, eventually say they face many difficulties. in their opinion, the school should have forms of punishment where children who need specialized treatment intervention receive a special education. While the philosophy of inclusive education sees the schools as an institution of vocational education, not only associated with academic achievement but where children are educated and adapt to the norms of the society. This demands the introduction of training for teachers and intervention plans to influence the deep recognition of positive discipline methods by teachers and staff. The quality of the student relationships is an essential factor to the welfare of students and recently in Albania has been given special importance of this phenomenon. It is important to study this phenomenon based on the analysis of these type of relations. in this background, this study plans to understand how they build, preserve and maintain their relationship with students and other students who display aggressive behaviour. What are their cognitions, what are the beliefs they have built to manage relations with these students.

\section{Core problems about inclusive education}

Regarding international reports for inclusive education, we have a lot of good strategies and policies but they are not fulfilling the real needs of children, who behave aggressively in schools. If we take in consideration the physical infrastructure of the public schools, we can see that they are well reconstructed, having in consideration the space and the physic environment for adolescents. The classrooms in the urban middle schools are wide;full of light, but the number of pupils in the same classroom is approximately from 35 to 38 . This is not a small number and sometimes the classrooms are small for this number which increases constantly. It can be very difficult to feel comfortable in the classroom. Another problem exposed by teachers and instruction specialists nowadays is the phenomenon called: "the secret abandonment" of school. Pupils aged 12-13 and older, feel more free to leave the class during the lessons and go around the schools or in the community 
places around. This is a big problem for parents and teachers. Usually pupils who abandon single hours or even whole school day are related to problem behaviour, such as bad communication skills, aggressive behaviour, episodes of bullyism, and the use of various drugs. They arealso pupils assigned as students with low performance. These students are not afraid of leaving the school for single days or single hours, because they think that in the school there are no rules for exemption and they can be free to behave the way they prefer. The teachers often say that there are lots of difficulties handling these children. in each classroom there are two or three persons, who behave this way. This causes consequences for the other children in the classroom. If we imagine the classroom as a unit composed by many pupils, more or less in the same level of externalised behaviours, we can think about different strategies of managing them, but when in the classroom are also pupils with maladaptive behaviour, they mix the group and, as teachers often says, the entire class becomes difficult to handle. in addition, in the everyday reality of the school there are pupils who found lots of difficulty treating with the children who behave aggressively. Following the result of some researches, children who are rejected, tend to fall into two subgroups: rejected-aggressive and rejected-withdrawn. Rejected-aggressive children are physically aggressive and bullying toward peers, while rejected-withdrawn children are often the victims of aggression by other children. Both groups display maladaptive behavior that makes it difficult for these individuals to get along with other children. (Allison Ryan, Kathryn Wentzel, Sandra Baker, B. Brown , Helen Davidson, Kathryn LaFontana, Dec 23, 2009)

\section{Method}

The methodology selected for this study is qualitative methods. After the secondary data analysis, it was found that the studies in the world have brought important data for this phenomenon. Reviewing the literature, it is taken into consideration the trend of this concept and the continuity of the treatment. The Interview was the best tool to get the biggest amount of information from the students. The interview contained open questions to receive as much as possible information from the children. The interview questions were grouped in several categories which included important indicator to be explored. There was a systematic analysis of primary data which provided us with plenty of materials to build a hypothesis in our analysis of information. Members in this study were pupils aged $12-14$ as a target group, who were especially selected for study. Some 20 pupils were divided into two groups. The semi structured interviews served as the material for this study which contained questions from the indicators to be analyzed. The Interviews data were compatible with the overall aim of the study and this tool has proved quite effective as a high value interpretative. There were questions about the information age, family status, parenting styles, as well as open questions where students were invited to give their opinions freely about the relations they have with aggressive pupils.

The pupils in the school environment face a lot of difficulties to be part of a group and also interactive part of the school system. Very few of them found difficulties maintaining the relationships with other pupils who represent aggressive behaviour.

\section{Participants}

The participants on this study were 20 pupils, part of a classroom identified as disruptive classroom by the teachers.We have made five open interviews with the children with aggressive and disruptive behaviour in the classroom or in theenvironment of the school during the process of education, and after the interviews we have created two groups of 10pupils each. The reason of the groups was to get more information by the peer and understand the factor that maintainedthe problem of aggressively. The groups of pupils were openly questioned about therelationships between peers and between them and pupils particularly aggressive. Open questions also helped that each of them to have the opportunity to express their opinion on the reasons why these students behave in this way, aggressive and destructive to the classobjects and environment, to each other and to the teachers. Some five children were the pupils who were characterized with more episodes ofaggressive behaviour and some 10 of them were pupils who have normal behaviour condition as said by the teacher.

\section{Procedure}

The procedure started with the individual interviews with five pupils with aggressive and disruptive behaviour. Then it was combined two focus groups divided by 10 pupils for each group in the psychologist's cabinet. Permission from parents, school management and teachers was takenfor the interviewing. The individual interviews were conducted in the office of the school psychologist; each of them lasted from 50-60 minutes with pupils with aggressive and destructive behaviour. It was explained to the students the reason and purpose of the study interview. It was explained that these data would be 
used for a study on aggressive behaviour and the importance that had the communication between peers to stop or maintain the aggressive behaviours. It was also considered that their identity will be kept confidential and we will not be utilized for other purposes.

The group interviews of 10 pupils took place in the school psychologist's cabinet. Just in the begging of the interviews it was explained to the students the reason and purpose of the study interview. It was explained that these data would be used for a study on aggressive behaviour and the importance that had the communication between peers to stop or maintain the aggressive behaviours. It was considered that their identity will be kept confidential and we will not be utilized for other purposes. I use a dictaphone for the group interviews to have in detail all the information of the pupils.

\section{Results}

The purpose of this study is to evaluate the role of the peers in the communication with other children, who present aggressive behaviour in the classroom environment. in this way, the interviews were orientated and focused on gathering information from the pupils on how they react during anaggressive situation between them; on how they resolve the aggressive situation in that moment; on how they communicate with the aggressive and disruptive pupils in their classroom; on how the relationship as the most important factor, between them and the teacher reflect in the best solution without aggressive elements etc.

The study began with the individual interviews, so the result that are presented in this first part are the result of the aggressive and disruptive pupils. The results of the individual interviews with the pupils who represent aggressive behaviour especially were focused in their opinion and how they think about their behaviour; about their point of view; about their type of solution to resolve the situation before acting aggressively; as well as about the communication with other pupils and with the teachers.

The answers of the pupils during the individual interviews show that the relationship between them and the teacher is not so good. They don't have a constructive relation with her. On the other side they feel that the friends of the classroom accept and love them, even if behave aggressively. They understand that their behaviour is not so correct, but most of them don't know why they react this way.

One of the initial questionsis: "What kind of relationship do you think you have with your teacher?" The $90 \%$ of the pupils responded to this question with a contradictory answer: "I have a normal relationship. She criticises me each time I do something wrong." Only two of the pupils, 10 \% responded: "I don't know, I don't have a relationship with the teacher of my class."

As we mentioned before the relationship between pupils and teacher is one of the most important factor. for this reason the questions are focused in the type of the relationship. in another question: "What are the reactions of the teacher and how does she behave when you are part of an incident in the classroom example: you've started to abuse your friend in the classroom or another pupil abuses you?". in this open question they answered differently because each pupil had different point of views and different experiences.

Some of them answered that especially when he/she started to offend or physically abuse his friend, the teacher criticized him infront of the other, than together they compiled a form about the incident, or another answer was that every time that he/she is part of an aggressive incident the teacher leaves an individual appointment with the school psychologist and if the things do not work, the teacher and the psychologist meet with the parents of the children.

Regarding the second part of the question: ... when the other abuse or offend him in the classroom..... - most childrenanswered that the teacher proclaims almost all them as responsiblefor the situation, and they said that most of the time she says: "You are guilty as the other peer, you have done something for things to be like this."

Another important question was about the communication that these pupils have with the other peers in the classroom.

"What kind of relationship do you have with the other pupils? Do you feel accepted, loved by them most of the time?"

Almost all the pupils respond that they feel accepted and loved by the other, but when the incident occurred in classroom the class is divided in two groups. One of the groups is who loves and accepts them, the other group is the part that doesn't want and don't like this kind of behaviours happening in the classroom.Some pupils also criticize them or support them to change. The other peers do not talk but only dislike this behaviour. 
Another question was about the thinks that they like/dislike in the communication with the teacher. Most of them express the idea that one thing that the teacher shouldn't do is to criticizes them especially in front of the other. They thing that they don't have a good relationship, and most of the time the teacher don't explain or help them improve in behave. "She is too rude with me. I want to know more about her, and she don't know more about me and my family problem. Every time she looks too busy to talk with us..."

The last important question that is helpful to present is : "If you can change or do something differently in your classroom, in your school and to your teacher what should it be?"

All the answers of the pupils were different about the changes that they could do.

One of them answers that: "I would like a different school, with a lot of sportive, entertainment and artistic activities. About the teacher I would like that my teacher improve with the relationship with me and my friends..."

Another answer was: "Everything in the school is fine, the thing that I would like to change is myself. I don't want to be a mass by I don't know how to stop being aggressive."

Another answer was: "My friends sometime make me feel bad, they offend me, and this think make me behave aggressively. I don't know how to do or what to change, the teacher even in this reason make me guilty and feel bad. If she some time can think before and then react?!"

The second part of the study contains the interviews with the two groups of 10 pupils each. The question were oriented and focused on the main idea of this study: - How the support of the teacher reflect and help improving the pupils in their aggressive behaviours and how the communication between them helps to change the behaviour?

Some of the questions below show a slightly different picture than the responses of children with aggressive and destructive behaviour. It is understandable that the groups formed with 10 pupils had their diversity, but they emphasized the significant role of the relationship between pupils and teacher. Also they emphasized the importance of the teacher's intervention in the prevention of the aggressive behaviour or the reaction of the teacher in the moment that had started to develop the aggressive.

From the information of the interviews it is clear that the best intervention to stop, prevent or resolve the aggressive behaviour it was the Relationship and communication between Teacher-pupils. This is not the only way to solve this problem, but is one of the most important which maintain success in the future.

One of the first questions was: "What kind of relationships do you have with the peers that have often become problem with their behaviour? Most of the students at the beginning of the interview stated that they have a good relationship, but when each of them began to cite cases or problems, the students began to add information to their opinion expressing dissatisfaction regarding their behaviour during the learning process often intrusive and not liked. Some of them admitted doing a little humour, that things often enlarged and moved by teachers and are always the same that are punished. Few of them admitted that they are not good students; always bring problems and make often seems to be in the spotlight.

Another important question addressed groups was: What are the things that you like and dislike on them? Many of the students said that they have many good things. - "Teachers do not recognize their problems in the family and it makes even frequently criticized, but up because they have these problems trying to see school as a place where they can have fun and maybe even their download the stress."- claims a student of the class.

A student claims that one of them has many friends, and claims that he behave aggressively sometimes, but also heis a good friend, loyal and very loving. Others argue that one of them often offendsthe others, insults and strikes. They claim also that some of them use insulting words and do not respect the figure and the authority of the teachers.

Some others argue that perhaps this is part of the character and whatever friends they behave, their behaviour will not change. Others are of the opinion that the teacher does everything for them, but often they do not hear, they insult authoritarian figure, and not have a good relationship, but it does not come from the teacher.

What are the reasons these children behave and do not change their aggressive behaviour?

In response to this question almost all children respond that there are several reasons they behave in this way. Someone claims that - they do not know how to behave differently. Someone else claims - he did not like the rules and the authority figures such as teachers or school institution. Someone claims that - he likes to behave as strong, fall in love and look to gain popularity. Someone claims that - the fact that they're all involved in the learning process cure them to invent things and situations through which to attract attention. 
This was a question that divided the group in three different ways how they behave in the moment of a situation or fight in the classroom. "How do you respond when an aggressive incident has just begun or start fights in the classroom?"

One of the ways they behave was: "I only see. I don't react or shout or call the teacher. It's not my business."

Some of them said that 'I'm afraid to act. If I inform the teacher, the peer can fight with me, or simply -they are not at all interested or concerned about it. Is their work and have to take responsibility of their behaviours.

Opinions were as far above the first group belonged to students, who appear indifferent to the aggressive behaviour.

In the second group the students asserted that they intervene immediately to separate them or do not allowed spoiling banks, doors, and other objects within the class. According to them, this can be solved by calling teachers, but their sense of immediate stoppage of action was to it immediately and after discussion with the teacher, and conversation.

In the third group of opinions on this question, they said that they call and inform the teachersimmediately, making them aware of what had happened or what may happen soon.

\section{Another question: "What is the best way to prevent aggressive behaviour?"}

The pupils presented several alternative methods of intervention, such as: informing the parents, withdrawal of conduct, written notice to the Director, communicating with other pupils of creating focus groups, communication among peers and communication and development of the relationship between teacher and children.

A large part of pupilssaid that communication between them is very effective, and seems to help them change behaviours. This relationship is stable if there's more communication between teachers and children. They alleged that the teacher is professional, knows and recognizes other ways to understand how the spiritual world of the child is, as well as has life experience more than they do, which can help a child with aggressive behaviour to change and behave in another positive way. It was a question in which students respond to almost all unanimously that the best solution would be conversations between preventive work created between teachers and pupils individually and / or group. This was deemed by them as the most efficient way. If this intervention is direct and consistent, the results are stable with the passing of time, and the resulting interventions and more successful method for inhibiting, preventing and extinguishing aggressive and destructive behaviour.

\section{Findings of Female Pupils}

The females are not aggressive and most of the time they are giving pacific and reasonable answers.

They express their feelings with compassion for the targeted pupils; they try to find reasons why they behave like this. "In their family they have a lot of personal and social and economic problems. Their parents are divorced and in my opinion this is the reason why my friend behaves like this".

To the question: "How do you respond when an aggressive incident has just begun or fightingstartsin the classroom?" some of them answered thatthey were afraid and the other girls said "I inform immediately the teacher." This expresses the feeling of being afraid. On the other hand, they showstrongness and will to help someone in danger."I can't stay and watch when the other offend or abuse someone."

\section{Finding of Males}

The same results and answers were found in the study. in the question mentioned above: "How do you respond when an aggressive incident has just begun or start fights in the classroom?" the boys didn't like to go and inform the teacher. They want more to resolve by themselves. "If l'll go to inform the teacher they will call me spy." "We are strong and we can resolve it between ourselves."

But in the last answer all together male and female respond that the best solution and intervention is the relationship and the communication between them and the teacher. This shows that both male and female pupils recognize that this is the best way to stop and prevent aggressive and disruptive behaviour. in the other way, when they have to collaborate and react by informing the teacher, they are not so ready to do this thing. They tend to resolve this kind of problems with each other, directed by the "rules of the street". 


\section{Discussion}

The study's results show that the intervention of the teachers or an adult in cases when the conflict involvedchildren is one of the best ways to prevent and stop aggressive and disruptive behaviour. During the interviews the children that present aggressive behaviour were too closed and manifested resistance at the begging. Some of them were too conservative in their answers, but the others were too open and expressed all their opinions, experience and feelings about this type of situations, relationship and the communication.

During the interviews with the groups they were too open, motivated for the process and gave a lot of information that may create an important path for recommendation for the future.

The school that took part and helped the process of this study was helpful by providing the permission, the premises to complete the interviews and engaged the school psychologist and teachers.

This qualitative research shows that in this little environment - the classroom with aggressive and disruptive behaviourreflect that the relationship and the type of communications help to improve, or to change the behaviour. It is understandably that this is the first step. It was recognized what kind of think help improve the behaviour. At the present, we know that the second step is to inform the teacher about the type of communication and type of techniques that are successful to use with pupils that present aggressive and disruptive behaviour.

\section{References}

[1] -Baron, R.A, Richardson D.R; (1994); "Human Aggression”;New York: Plenum. 2nd ed.

[2] -Barth, J.M., Dunlap, S.T., Dane, H., Lochman, J.E.,\& Wells, K.C.; (2004);"Classroom environment influences on aggression, peer relations, and academic focus."; Journal of School Psychology, 42, 115-133.

[3] -Berkowitz, L;(1993); "Pain and aggression:some findings and implications" ; Motiv. Emot; 17:277-93

[4] -Brophy, J.E; (1996);“Teaching problem students." New York: Guilford Press.

[5] -Bushman, B.J, Anderson C.A; (2001); "Is it time to pull the plug on the hostile versus instrumental aggression dichotomy?" ;Psychol. Rev.108:273-79.

[6] -Coie, J.D., \& Dodge, K.A; (1998);"Aggression and anti-social behavior" in N. Eisenberg (Ed), Handbook of child psychology: Vol. 3; Social, emotional, and personality development 779-862; New York: Wiley.

[7] -Colvin, G., Kame"enui, E.J., \&Sugai, G; (1993);"Reconceptualizingbehavior management and school-wide discipline in general education."; Education and Treatment of Children, 16, 361-381.

[8] -Dishion, T.J., McCord, J., \&Poulin, F.; (1999);"When interventions harm: Peer groups and problem behavior.";American Psychologists, 54, 755-764.

[9] -Geen, R.G; (2001); "Human Aggression" (2nd ed.); Oxford, UK: Taylor \& Francis.

[10] -Hawkins, J.D., VonCleve, E., \& Catalano, R.F; (1991); "Reducing early childhood aggression: Results of aprimary prevention program."; Journal of the AmericanAcademy of Child and Adolescent Psychiatry, 30,208217.

[11] -Hughes, J.N., Cavell, T.A., \& Jackson, T.; (1999); "Influence of the teacher-student relationship on childhood conduct problems: A prospective study"; Journal of Clinical Child Psychology, 28, 173-184.

[12] -Kellam, S.G., Ling, X., Merisca, R., Brown, C.H., \&lalongo, N.; (1998);"The effect of the level of aggression in the first grade classroom on the course and malleability of aggressive behavior in middle school.";Development and Psychopathology, 10, 165-185.

[13] -Lewis, T.J., \&Sugai, G; (1999);"Effective behavior support: A systems approach to proactive schoolwide management."; Focus on Exceptional Children, 31, 1-24.

[14] -Oliver R, Wehby J, Daniel J.; (2011); "Teacher classroom management practices:Effects on disruptive or aggressive student behavior."Campbell Systematic Reviews 2011.4

[15] -Rose, L.C., \& Gallup, A.M; (2005); "The 37 th annual Phi Delta Kappa/Gallup poll of the public"s attitudes toward the public schools"; Phi Delta Kappan, 87(1), 41-57.

[16] -Thomas, D.E; Bierman, K.L, (2006) "The impact of classroom aggression on the development of aggressive behavior problems in children"; Development and Psychopathology 18, 471-487.

[17] -Tversky, A.; (1977); "Features of similarity"; Psychological Review, 84, 327-354. 